\title{
SUDDEN CARDIAC DEATH: VULNERABILITY OF ATHEROSCLEROTIC PLAQUE IN CORONARY ARTERIES
}

\author{
Sumaira Bukhsh, Samia Nasreen*, Hassan Tariq**, Syed Salman Ali***, Muhammad Umer***, Nadeem Zafar**, Hafeez Ud Din** \\ Combined Military Hospital Malir/National University of Medical Sciences (NUMS) Pakistan, *Combined Military Hospital/National University of Medical \\ Sciences (NUMS) Rawalpindi Pakistan, **Armed Forces Institute of Pathology/National University of Medical Sciences (NUMS) Rawalpindi Pakistan, \\ ${ }^{* * *}$ Combined Military Hospital Abbottabad/National University of Medical Sciences (NUMS) Pakistan, ${ }^{* * * * P a k i s t a n ~ N a v a l ~ S h i p ~ H o s p i t a l, ~ K a r a c h i ~ P a k i s t a n ~}$
}

\begin{abstract}
Objective: To assess the vulnerability of atherosclerotic plaque in coronary arteries of individuals dying of ischemic heart disease.

Study Design: Cross sectional study.

Place and Duration of Study: Histopathology department, Combined Military Hospital Lahore, from Nov 2016 to Nov 2017.

Methodology: A total of 43 cases were taken in the study. The Autopsy specimens from the bodies of people dying suddenly of ischemic heart disease were taken into the study. Tissues showing autolytic changes and patients dying with coronary artery disease after corrective procedure like stenting and bypass were excluded.

Results: Out of 43 cases, 35 (81.4\%) cases were positive for cluster of differentiation 68 (CD 68), 34 (79\%) cases were positive for cluster of differentiation 105 (CD 105) \& 36 (83.6) cases were positive for nuclear factor kappa-light-chain-enhancer of activated B cells (NF-Kb).

Conclusion: People who had died of ischemic heart disease have more vulnerable plaque in their coronary arteries as compared to the people who had died of non-ischemic cause. Early recognition of the un-ruptured plaque is important for the treatment strategies.
\end{abstract}

Keywords: Atherosclerotic plaque, Cluster of differentiation 68, Cluster of differentiation 105, Nuclear Factor-kappa-light-chainenhancer of activated B cells, Vulnerability.

How to Cite This Article: Bukhsh S, Nasreen S, Tariq H, Ali SS, Umer M, Zafar N, Din HU. Sudden Cardiac Death: Vulnerability of Atherosclerotic Plaque in Coronary Arteries. Pak Armed Forces Med J 2021; 71(5): 1548-1552. ～doi: https://doi.org/10.51253/pafmj.v71i5.3621

This is an Open Access article distributed under the terms of the Creative Commons Attribution License (https://creativecommons.org/licenses/by-nc/4.0/), which permits unrestricted use, distribution, and reproduction in any medium, provided the original work is properly cited.

\section{INTRODUCTION}

Cardiovascular disease will be the leading cause of death in the year 2020. ${ }^{1}$ An unexpected death happening within a short amount of time due to a cardiac cause in a person with a known or unknown cardiac disease in whom no previously diagnosed fatal condition is apparent, is labeled as "sudden cardiac death" (SCD). SCD is associated with underlying coronary artery disease (CAD) in most of the cases. In a population based cross sectional survey on 320 randomly selected adults in Pakistan, the frequency of CAD is reported to be $26.9 \%$ that is $23.7 \%$ in men and $30 \%$ in women. A local study at Pakistan showed that in symptomatic females $72 \%$ had CAD. ${ }^{2}$ In India, a population based survey showed CAD prevalence in both genders was found to be $11 \%$ in the urban population and $7 \%$ in the rural population, including age group from 20-79 years. ${ }^{3}$

Atherosclerosis refers to the progressive process in medium and large sized arteries associated with the

Correspondence: Dr Sumaira Bukhsh, Consultant Histopathologist, Combined Military Hospital, Malir Karachi-Pakistan

Received: 17 Feb 2019; revision received: 12 Feb 2020; accepted: 25 Feb 2020 focal intimal lesions called atheromas or atherosclerotic plaques that may protrude into the lumen of vessel and eventually may lead to various complications. ${ }^{4}$

Two major types of plaques are known, depending on their vulnerability. The vulnerable plaque is the one that is prone to rupture, can cause thrombosis and other complications. ${ }^{5}$ The stable plaque is the one which shows less compensatory enlargement and gradually occludes the vessel lumen. Latest studies showed that it is basically the vulnerability of plaques, which causes acute complications rather than the degree of occlusion by the plaque. Pathophysiology of atheromatous plaque is extremely important for complete understanding of the $\mathrm{CAD}$, its clinical behavior and establishing treatment modalities. ${ }^{5}$

Atherosclerosis is related to the inflammation of vascular wall of chronic nature. A pan macrophage marker CD68 protein plays an important role in inflammation of the plaque. It is found that the risk of rupture of vulnerable plaques may be determined by degree of infiltration by macrophages. There is a structural homology between NF-kB proteins and the retroviral oncoprotein v-Rel; thus their classification is as NFKB 
AND Rel proteins. Five NF-kB transcription factors are important: RelB, RelA/NFkB-p65, c-Rel, NF-B2/NFkB$p 100 / p 52$ and NF-B1/NFkB- $p 105 / p 50$. Normal cellular processes are regulated by these factors. Various stimuli activate NF- $\mathrm{kB}$ that translocates in the nucleus resulting in the expression of genes related to several biological functions. Many inflammatory diseases are associated with inappropriate activation of NF- $\mathrm{kB}$. In normal coronary arteries the expression of NF- $\mathrm{KB}$ is not very detectable, but can be seen after injury. Thus NF$\mathrm{KB}$ has a vital role in atherosclerotic plaque. CD105 is a protein related with development of new vessels. The progress of atherosclerotic plaque is associated with inflammation, macrophages and revascularization. Thus, we have investigated the expression of these factors as they are expressed in vulnerable plaques. ${ }^{6}$

There are limited studies available for telling about the mechanisms of progression from an asymptomatic and stable to high-risk vulnerable plaque that may lead to rupture and thrombosis and thus myocardial infarction. Autopsy is an important source for knowing about the vulnerable plaque and its morphology, which may suggest the information of necrotic core size, fibrous cap thickness and inflammation. This study was thus designed to determine the vulnerability of atherosclerotic plaques in coronary arteries taken out from autopsy specimens in our setup.

\section{METHODOLOGY}

This cross sectional study was carried out at the histopathology department, Combined Military Hospital, Lahore, from November 2016 to November 2017. Sample size ( $\mathrm{n}=43$ at least) was calculated by using the WHO sample size calculator, including parameters: 95\% confidence level, $80 \%$ anticipated population proportion 2 and absolute precision to be 0.12 . Non-probability, consecutive sampling was used.

Inclusion Criteria: The autopsy specimens from the bodies of people dying suddenly of IHD as well as cases suspected dying of IHD, were taken into the study.

Exclusion Criteria: The coronary arteries with atherosclerotic changes were included in this study. Tissues showing autolytic changes were not included. Patients dying with CAD after corrective procedure like stenting and bypass were also excluded.

Approval of ethics committee of AFIP Rawalpindi was taken (ERC no. HSP-10/2015). Consent of next of kin had already been taken for postmortem examination of serving person.
Heart was dissected in the direction of blood flow. Serial cross sectioning of coronary arteries at $1 \mathrm{~mm}$ interval was done and representative sections from suspicious areas were taken while gross finding recorded in already designed proforma. Coronary arteries for various components of vulnerable plaques, number of foam cells, inflammatory cells, calcification and intraplaque haemorrhage and presence or absence of fibrous capsule all were assessed by simple microscopy. Immunohistochemistry was performed for neo-vascularization (CD105), macrophages (CD68) \& inflammatory factor (NF-KB), as per the manufacturer's guidelines and its results were interpreted on high power field objective. Data collection proforma of the deceased were filled while confounding factors were avoided by strictly following the inclusion and exclusion criteria. The results were verified by senior colleague to minimize bias.

Statistical analysis was done by using SPSS-20. Mean and standard deviation were calculated for the variables of quantitative nature like age of the patient. Frequency and percentage were calculated for variables of qualitative nature like scoring for the plaque vulnerability and immunohistochemistry. The results were shown by tables.

\section{RESULTS}

Total 43 patients with the age ranged from 38-75 years with mean age of $54.95 \pm 3.27$ years. In our study, most of the patients belonged to $4^{\text {th }} \& 5^{\text {th }}$ decades of life (Figure). All patients were males.

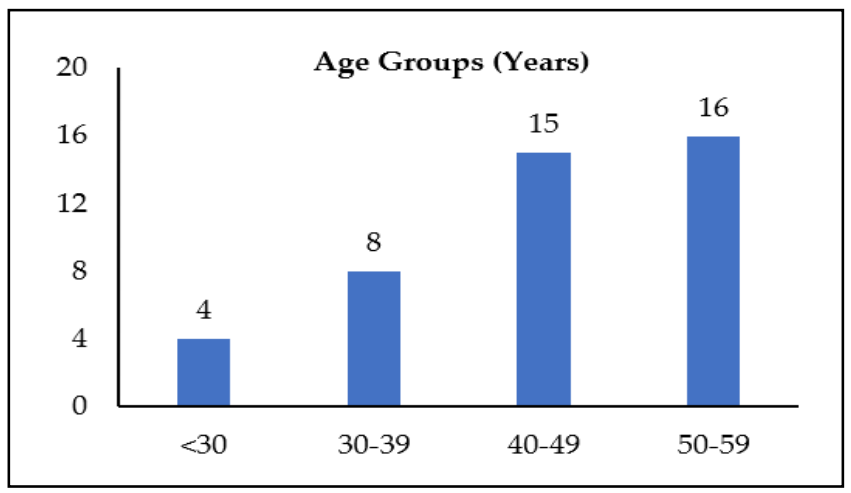

Figure: Age distribution $(n=43)$.

Thirty five cases of atherosclerotic plaques $(81.4 \%)$ showed positivity for CD68 while $8(18.6 \%)$ cases were negative. Thirty four cases of triple atherosclerotic plaque $(79 \%)$ showed positivity for CD105 while $9(21 \%)$ cases were negative. Thirty six $(83.7 \%)$ cases were positive for NF-kB while 7 (16.3) cases were negative. Thirty five $(81.4 \%)$ cases were showing presence of foam cells. Thirty five $(81.4 \%)$ cases showed presence of fibrous 
capsule. Thirty four (79\%) cases were having mononuclear cells (Table-I). Thirty five case showed vulnerable plaque with the significant $p$-value (Table-II). Distribution of different age groups and immunohistochemistry was also carried out (Table-III).

Table-I: Comprehensive histological characteristics of coronary atherosclerosis in autopsy specimen $(n=43)$.

\begin{tabular}{l|c}
\hline Parameters & $\mathbf{n ~ ( \% )}$ \\
\hline Foam Cell Presence & $35(81.4 \%)$ \\
\hline Fibrous Cap Presence & $35(81.4 \%)$ \\
\hline Mononuclear Cells Presence & $34(79 \%)$ \\
\hline Calcification & $16(37 \%)$ \\
\hline Intraplaque Haemorrhage & $1(2 \%)$ \\
\hline Vulnerable Plaque & $>80 \%$ \\
\hline Stable Plaque & $<20 \%$ \\
\hline Immunohistochemistry for CD68 & $35(81.4 \%)$ \\
\hline Immunohistochemistry for CD105 & $34(79 \%)$ \\
\hline Immunohistochemistry for NF-kB & $36(83.7 \%)$ \\
\hline Table-II: Stable vs vulnerable plaque percentage. \\
\hline Plaque Type & $\mathbf{n}(\%)$ \\
\hline Stable & $8(<20 \%)$ \\
\hline Vulnerable & $35(>80 \%)$ \\
\hline
\end{tabular}

neurohormonal changes; these all can cause ventricular tachycardia (VT) and ventricular fibrillation. After an attack of myocardial infarction (MI), complex premature ventricular contractions (PVCs) reflect a greater risk of sudden death.

Sudden death can also occur without presence of any cardiac pathology. The most common cause is the autosomal dominant long QT syndrome, which causes cardiac irritability and episodic ventricular arrhythmias. Mutation of the five different genes causes this disorder. These genes encode cardiac channel components including potassium and sodium channels.

The plaque development is an inflammatory but non-infective process characterized by complications of inflammatory cells accumulation and hemorrhage. ${ }^{10}$ As the NF-kB expression is associated with the inflammation of atherosclerotic plaque, our data suggested that the NF- $\mathrm{kB}$ activation in unstable plaque was higher. This indicates that increased inflammation occurs in unstable plaque than the stable plaque. Overall, our

Table-III: Distribution of age group \& Immunohistochemistry.

\begin{tabular}{l|c|c|c|c|c|c|c|c}
\hline \multicolumn{2}{c|}{} & \multicolumn{9}{c}{ Immunohistochemistry } \\
\cline { 3 - 9 } \multicolumn{2}{c|}{} & CD68+ve & CD105+ve & NFkB +ve & $\begin{array}{c}\text { CD68 \& CD } \\
105+v e\end{array}$ & $\begin{array}{c}\text { CD105 \& } \\
\text { NFkB +ve }\end{array}$ & $\begin{array}{c}\text { CD68 \& } \\
\text { NFkB +ve }\end{array}$ & $\begin{array}{c}\text { CD68, 105 \& } \\
\text { NFkB +ve }\end{array}$ \\
\hline \multirow{3}{*}{$\begin{array}{l}\text { Age Group } \\
\text { (years) }\end{array}$} & $30-39$ & - & - & $1(25 \%)$ & - & - & $1(25 \%)$ & $2(50 \%)$ \\
\cline { 2 - 9 } & $40-49$ & $1(6.6 \%)$ & $2(13 \%)$ & - & - & $1(12.5 \%)$ & $2(25 \%)$ & $7(87.5 \%)$ \\
\cline { 2 - 9 } & $50-59$ & - & $11(6 \%)$ & - & $1(6 \%)$ & $1(6 \%)$ & $1(6.6 \%)$ & $7(48 \%)$ \\
\hline
\end{tabular}

\section{DISCUSSION}

SCD is defined as an unexpected and early death resulting from a cardiac cause, that is (within $60 \mathrm{~min}$ ) with or without the onset of symptoms ${ }^{7}$. In majority of the cases in adults, sudden cardiac death is usually the first clinical manifestation and complication of IHD. Common causes of SCD are cardiac arrythymias. Fifty percent of all cardiac deaths can be classified as SCDs. Patients usually dying out of hospital die as a result of cardiac arrest. ${ }^{8}$

The final mechanism of SCD is often a lethal arrhythmia for example ventricular fibrillation or a systole. Ischemic injuries can also damage the conduction system and can cause cardiac electromechanical instability. However, usually the fatal arhythmia are initiated by electrical irritability of myocardium, damaged by ischemia or any other cellular abnormality; that may be far away from the conduction system. ${ }^{9}$

Altered calcium (Ca), potassium (K) levels, mutations of sodium channels $(\mathrm{Na})$ resulting in increased automaticity or reentry with single direction block and study demonstrates that the basic elements/mediators of an inflammation including macrophage specific CD 68, NF-kB and neovascularization CD105 are highly expressed in unstable plaques when compared with the stable plaques. ${ }^{11,12}$

The study revealed 35 autopsy specimens (>80\%) showing vulnerable plaque and 8 autopsy specimens $(<20 \%)$ showing stable plaque, with a $p$-value 0.0001 .

This showed a strong association between the coronary atherosclerotic plaque vulnerability and ischemic cardiac disease, which was in accordance to the 2007 studies conducted by Cheruvu et al, on 50 whole hearts that were taken from the patients died of cardiovascular $(n=33)$, non-cardiovascular $(n=13)$ and unknown causes $(n=4)$. They studied the distribution and the frequency of a vulnerable and ruptured plaque in human coronary arteries. They concluded that the frequency of vulnerable and ruptured plaque was more in individuals dying as a result of cardiovascular cause than those who died of non-cardiovascular or unknown cause. $^{13}$ 
The result of this study was also in accordance with a study carried out by Burke et al, on the hearts of 113 men with CAD that had died suddenly. They found severe narrowing of the coronary artery by an atherosclerotic plaque without thrombosis in 54 patients. Out of these 54 patients, 41 patients had rupture of vulnerable plaque in coronary arteries. ${ }^{14}$

Some studies have shown that fibroatheromas having thin cap (vulnerable plaque) are most abundant in patients dying of acute coronary event and are least common in those with the incidental non-coronary deaths. Virmani et al, showed that the vulnerable plaques are most common in coronary arteries of the patients dying of acute myocardial infarction and are least frequent in those with plaque erosion. ${ }^{15}$ Results of this study was consistent with these studies. An association was found between IHD and vulnerable plaques with atheromatous changes in the coronary arteries of the people who died suddenly.

Foam cells presence is a very important criterion as well for vulnerable plaque. In this study, foam cells were there in $81.4 \%$ cases, and same was observed by Vink et al, Falk et al and Davis et al. ${ }^{16-18}$

The present study revealed that $81.4 \%$ cases had fibrous cap fulfilling thus the criteria for plaque vulnerability, with a significant $p$-value of 0.001 . This is statistically very significant. This is consistent with the autopsy study conducted by Virmani et al, which showed the presence of a vulnerable plaque with a necrotic core and an overlying thin fibrous cap of 65um made up of collagen type 1 , infiltrated by macrophages in the coronary system of the patients who had died of acute myocardial infarction. ${ }^{15}$

Inflammatory cells infiltration is also seen in vulnerable atherosclerotic plaque as compared to the stable plaque. As in previous studies fully developed plaques contain variable amounts of inflammatory cells, however largest concentrations were there in the lipid rich lesions where they infiltrate the attenuated cap, the shoulder parts of the lesions or both. ${ }^{19}$ There was an association seen between the availability of inflammatory cells in the lesions and the severity of various unstable ischemic syndromes as shown in study of Lappegard et al. ${ }^{20}$

This study revealed inflammatory cells in 79\% cases, with a significant $p$-value of 0.001 , showing increased inflammatory cells in vulnerable plaque and same was observed in previous studies. Another goal of this study was to identify the macrophages by CD 68, angiogenesis by CD 105 and inflammation by NF-kB. Simi- larly, in a recent study conducted by Libby et al, on immunohistochemical markers CD68 was used to assess the unruptured plaques of the coronary arteries. ${ }^{21}$

\section{CONCLUSION}

Patients dying as a result of IHD do have vulnerable plaque in their coronary arteries more commonly. Autopsy studies have revealed that the large lipid core and thin cap with increased inflammatory cells are more frequently observed in the non-ruptured atherosclerotic lesions.

This study suggests an early recognition of the unruptured plaque for the treatment strategies. The details into morphological features of vulnerable plaque in patients of sudden cardiac death will lead to better identification of the patients at high risk of acute coronary syndrome and will help in development of new diagnostic and therapeutic strategies for the treatment of IHD. The incidence of the sudden cardiac death will thus be reduced. Finally, the study can be helpful in future search of vulnerable patients by using the genomic and proteomic techniques.

\section{Conflict of Interest: None.}

\section{Authors' Contribution}

SB: Data collection, data analysis, conception, interpretation of data and data design, SN: Proof reading, HT: Data collection, data analysis and conception, SSA: Data collection, data analysis and conception, MU: Data collection, data analysis and conception, NZ: Revision of data, HUD: Supervision of data.

\section{REFERENCES}

1. Dehghan M, Mente A, Zhang X, Swaminathan S, Li W, Mohan V, et al. Associations of fats and carbohydrate intake with cardiovascular disease and mortality in 18 countries from five continents (PURE): a prospective cohort study. Lancet 2017; 390 (10107): 2050-2062.

2. Naz S, Mubarik A, Jamal S, Malik TM. Assessment of atherosclerotic plaque vulnerability of coronary arteries in cases of sudden cardiac death. Pak Armed Forces Med J 2010; 60(1): 21-25.

3. Harikrishnan S, Sarma S, Sanjay G, Jeemon P, Krishnan MN, Venugopal K, et al. Prevalence of metabolic syndrome and its risk factors in Kerala, South India: Analysis of a community based cross-sectional study. PloS One 2018; 13(3): 1-6.

4. Aboonabi A, Rose'Meyer R, Singh I. The association between metabolic syndrome components and the development of atherosclerosis. J Hum Hypertens 2019; 210(3): 1-2.

5. Mori H, Finn AV, Kolodgie FD, Davis HR, Joner M, Virmani R Atherogenesis: The development of stable and unstable plaques. in physiological assessment of coronary stenoses and the microcirculation 2017, [Internet] Available from: https://link.Springer.com/book/10.1007\%2F978-1-4471-5245-3

6. Annunziata CM, Stavnes HT, Kleinberg L, Berner A, Hernandez $\mathrm{LF}$, Birrer MJ, et al. Nuclear factor $\mathrm{kB}$ transcription factors are coexpressed and convey a poor outcome in ovarian cancer. Cancer 2010; 116(5): 3276-3284.

7. Brignole M, Moya A, de Lange FJ, Deharo JC, Elliott PM, Fanciulli A, et al. ESC Guidelines for the diagnosis and management of syncope. Eur Heart J 2018; 39(21): 1883-1948.

8. Triqui B, Benyettou A. Cardiac arrythmia classification by neuronal networks (MLP). Online J Sci Technol 2018; 8(1): 123-134. 
9. Haqqani HM, Chan KH, Kumar S, Denniss AR, Gregory AT. The contemporary era of sudden cardiac death and ventricular arrhythmias: basic concepts, recent developments and future directions. Heart Lung Circulat 2019; 28(1): 1-5.

10. Chyu KY, Shah PK. The role of inflammation in plaque disruption and thrombosis. Rev Cardiovasc Med 2019; 2(2): 82-91.

11. Pauli J, Tsantilas P, Kallmayer M, Maegdefessel L. Time-dependent biopathological alternations in carotid atherosclerotic plaques from symptomatic patients. Atheroscl 2019; 287(2): e269-e275.

12. Basatemur GL, Jørgensen HF, Clarke MC. Vascular smooth muscle cells in atherosclerosis. Nat Rev Cardiol 2019; 231(14): 1-8.

13. Cheruvu PK, Finn AV, Gardner C, Caplan J, Goldstein J, Stone GW, et al. Frequency and distribution of thin-cap fibroatheroma and ruptured plaques in human coronary arteries: a pathologic study. J Am Coll Cardiol 2007; 50(10): 940-949.

14. Burke AP, Taylor A, Farb A, Malcolm GT, Virmani R. Coronary calcification: insights from sudden coronary death victims. Zeitschrift Für Kardiol 2000; 89(2): S049-53.

15. Virmani R, Burke AP, Kolodgie F. Morphological characteristics of coronary atherosclerosis in diabetes mellitus. Can J Cardiol 2006; 22(76): 81B-4B.
16. Vink A, Schoneveld AH, van der Meer JJ, van Middelaar BJ, Sluijter JP. In vivo evidence for a role of toll-like receptor 4 in the development of intimal lesions. Circulat 2002; 106(15): 1985-1990.

17. Falk E. Why do plaques rupture. Circulat 1992; 86(Suppl-6): III30-42.

18. Criqui $\mathrm{MH}$, Heiss G, Cohn R, Cowan LD, Suchindran $\mathrm{CM}$, Bangdiwala $\mathrm{S}$, et al. Plasma triglyceride level and mortality from coronary heart disease. N Eng J Med 1993; 328(17): 12201225.

19. Tulamo R, Frösen J, Hernesniemi J, Niemelä M. Inflammatory changes in the aneurysm wall: a review. J Neurointervent Surg 2018; 10(Suppl-1): i58-67.

20. Lappegard J, Ellingsen TS, Hindberg K, Mathiesen EB, Njølstad I, Wilsgaard T, et al. Impact of chronic inflammation, assessed by hs-crp, on the association between red cell distribution width and arterial cardiovascular disease: the tromsø study. TH Open 2018; 2(02): e182-189.

21. Libby P, Pasterkamp G, Crea F, Jang IK. Reassessing the mechanisms of acute coronary syndromes: the "vulnerable plaque" and superficial erosion. Circul Res 2019; 124(1): 150-160. 